\title{
PAPILLARY THYROID CARCINOMA IN A THYROGLOSSAL DUCT CYST (TDC) WITHOUT A THYROID PRIMARY
}

Zeynep CANTURK ${ }^{1}$, Fatma Tugba CATAN ${ }^{2}$, Berrin CETINARSLAN ${ }^{1}$, Ilhan TARKUN ${ }^{1}$, Ozlem Zeynep AKYAY $^{1}$, Alev SELEK ${ }^{1}$

'Section of Endocrinology, Department of Internal Medicine, Kocaeli University, Kocaeli, Turkey

${ }^{2}$ Department of InternalMedicine, Kocaeli University, Kocaeli, Turkey

\section{OBJECTIVES}

Thyroglossal duct cyst (TDC) is a developmental abnormality of the thyroid gland. Malignancy arising from this duct is very rare. Due to embryological remnants of thyroid tissue located in the TDC, all malignant tumors which develop in the thyroid gland may also develop in the TDC. In case of malignancy, the most probable diagnosis is papillary thyroid carcinoma.

\section{CASE}

We present a 27 -year-old female patient complaining of a midline neck mass. Ultrasonography revealed cystic lesion of $32 \times 26 \mathrm{~mm}$ includes solid zone with the calcifications approximately $15 \mathrm{~mm}$ at the midline neck and a $4.5 \mathrm{~mm}$ cystic nodule at the right lobe of thyroid gland. Fine

needle aspiration biopsy was nondiagnostic. She was operated and histopathologically diagnosed as papillary thyroid carcinoma arising from the thyroglossal canal. With the suspicion of metastasis of the primary thyroid papillary carcinoma total thyroidectomy and central lymph

node dissection were performed. Histopathological evaluation revealed colloid goiter and reactive lymph nodes as benign cytology. There was no residual thyroid tissue or any lymph nodes on post-operative neck ultrasonography. Postoperative serum thyroglobulin level was 9.9 $\mathrm{ng} / \mathrm{ml}$ and anti-thyroglobulin was negative when TSH level was high ( $>100 \mathrm{mIU} / \mathrm{L})$. Radioactive iodine ablation treatment was planned.

\section{CONCLUSIONS}

Ectopic papillary thyroid carcinoma may also develop in the TDC due to embryological remnants of thyroid tissue located in the TDC. Therefore the clinician should have a high index of suspicion upon encountering papillary thyroid carcinoma of the TDC to differentiate de novo papillary thyroid carcinoma in the TDC from those originating from the thyroid gland. 